\title{
Investigating the Roles of Organizational Culture, Leadership Style, and Employee Engagement in Knowledge Transfer
}

\author{
Dr. Mohammad Hossein Moshref Javadi \\ Faculty member of Management, Department of Business Administration \& Economics \\ University of Isfahan, Isfahan, Iran \\ E-mail: MHMJ20032003@yahoo.com
}

\section{Anahita Ahmadi}

Ph.D. Student of Management, Department of Business \& Economics, University of Isfahan, Isfahan, Iran

E-mail: a.ahmadi468@yahoo.com

DOI: $\quad 10.6007 /$ IJARBSS/v3-i9/261 URL: http://dx.doi.org/10.6007/IJARBSS/v3-i9/261

\begin{abstract}
Knowledge transfer as new concept which attracts scholars' attentions can be improved by factors such as organizational Culture, leadership style, and employee engagement. As the main objective of the preset study, three organizational, managerial and membership aspects were considered as main factors which can influence knowledge transfer through organizations. To gain this goal, the proposed model has investigated the relationship between three variables of organizational Culture, leadership style, employee engagement ad knowledge transfer through structural equation modeling method and by AMOS software. The present study has conducted 250 professionals working in over 8 software organizations. All data was gathered by multi dimensional questionnaire. The results indicated that all these three variables strongly related to knowledge transfer in organizations.
\end{abstract}

Keywords: organizational Culture, leadership style, employee engagement, Knowledge transfer, SEM

\section{Introduction}

In some cultures employees have sufficient knowledge of their work and tend to help each other meet high levels of mutual satisfaction needs and are oriented toward their clients. This culture can improve job commitment. This type of culture can enhance knowledge transfer.

Leadership scholars are quite familiar with the often convoluted and problematic path that leadership theory has taken. Despite these challenges, leadership is currently considered a mature field (Hunt \& Dodge, 2000) even though this maturity has not been achieved without 
considerable growing pains. The concept of leadership can be traced back to ancient times, with leader traits, behaviors, and processes discussed in ancient writings of China, Egypt, Greece, India, Israel, Iraq, and Italy. However, systematic study is much more recent (from the 20th century on) (Coglisera et al., 2004), as Brocke and Sinnl's survey which considered two aspects of culture: the manifestation culture and the scope of the referenced group (Brocke et al. 2011).Employee engagement is a relatively young field compared with its counterparts in management. High number of engaged employees will help an organization attract more talented people while disengaged employees will cost an organization such as lower productivity, higher absenteeism, recruitment and training cost. Bates (2004) noted the presence of an engagement gap in the United States of America and estimated that half of the United States workforce are disengaged costing the country's businesses lost of productivity worth $\$ 300$ billion annually. Supporting this evidence, an Australian researcher, Hooper (2006), also noted that the Australian economy loses about $\$ 31$ billion per annum as a result of the nation's employees' disengagement.

Knowledge transferring what attracts scholars' attentions can be influenced by three factors of organizational Culture, leadership style, and employee engagement. In the present study, we first provide related researches in these fields and then test the proposed model by SEM method.

\section{Theoretical framework}

\subsection{Culture}

Culture is a broad and blurry concept because it is associated differently depending on the context. More than 150 definitions of culture have been identified by Kroeber and Kluckhohn (1952). Still, many of the definitions have a common theme. For example, Hofstede (2005) considers culture to be the "collective programming of the mind" while Schein (2004) suggests that a group learns "a pattern of shared basic assumptions."

Culture is described as the organization's behavioral expectations of its employees and the way things are done in the organization (e.g., support, conformity). Culture is defined only at the organizational or work unit level and captures the behavioral expectations and norms that characterize the way work is done in an organization or work unit (Glisson et al., 2006).

The culture is sometimes created by the initial founder of the firm (such as Walt Disney). Sometimes it emerges over time as an organization encounters and overcomes challenges and obstacles in its environment (as at Coca-Cola). Sometimes it is developed consciously by management teams who decide to improve their company's performance in systematic ways (as General Electric did). Simply stated, successful companies have developed something special that supersedes corporate strategy, market presence, and technological advantages. Although strategy, market presence, and technology are clearly important, highly successful firms have capitalized on the power that resides in developing and managing a unique corporate culture (Cameron and Quinn, 2006). This power abides in the ability of a strong, unique culture to reduce collective uncertainties (that is, facilitate a common interpretation system for members), create social order (make clear to members what is expected), create continuity (perpetuate key values and norms across generations of members), create a collective identity and commitment (bind members together), and elucidate a vision of the future (energize forward movement) (Trice and Beyer, 1993). Organizational culture, which is defined as the way 
things are done in an organization, shapes employee behavioral expectations and norms (Verbeke, Vlogering, \& Hessels, 1998).

They also share several common elements in understanding organizational culture, although they use different categories for classification. Organizational culture is mainly categorized into constructive culture $(\mathrm{OCl}, \mathrm{OCP})$ or proficient culture $(\mathrm{OSC})$ versus defensive culture $(\mathrm{OCl}, \mathrm{OCP})$ or rigid/resistant culture (OSC). For example, in the category of constructive or proficient culture, employees possess behavioral expectations and norms of achievement, innovation, competence, cooperation, supportiveness, responsiveness, and emphasis on reward for their performance (Cooke \& Szumal, 2000; Glisson, 2007).

In this type of culture, employees have sufficient knowledge of their work and tend to help each other meet high levels of mutual satisfaction needs and are oriented toward their clients. In contrast, in the category of defensive or rigid/resistant culture, employees have behavioral expectations and norms of approval, conventionality, dependency, opposition, power, formulation, and suppression (Cooke \& Szumal, 2000; Glisson, 2007). In this type of culture, employees follow conventional rules, tend to conduct their task to protect their lower status, and they orient toward their tasks rather than the client's well-being (Shim, 2010).

Empirical research has produced an impressive array of findings demonstrating the importance of culture to enhancing organizational performance (Cameron and Ettington, 1988; Trice and Beyer, 1993). There exists the relationship between organizational culture and the effectiveness of an organization. For example, Ouchi (1981) found that focusing on humanistic organizational values - such as motivation, cooperation, and emphasis on rewards - had positive financial impacts on Japanese firms. An organization with positive culture where employees receive quick feedback and reward for their performance responds well to working environments and adapts well to changing circumstances (Deal \& Kennedy, 1982). Behavioral expectations and norms explaining organizational culture affect an employee's work attitudes and quality in service delivery (Glisson, 2007; Shim, 2010). For example, employees working in a defensive culture are less likely to provide high quality services for children and families than those with a constructive culture, because a defensive culture promotes passive reactivity and the avoidance of legal sanctions they may receive if they fail to provide the services. These poor work attitudes by employees, in turn, decrease the quality in service delivery (Shim, 2010).

\subsection{Leadership}

Leadership has been a major topic of research in psychology for almost a century and has spawned thousands of empirical and conceptual studies. Despite this effort, leadership research to date is somewhat disconnected and directionless (Zaccaro and Klimoski, 2001).

Therefore, more specific context-based research is required that acknowledges the unique facets of organizational cultures which include social, political, economic, technologic, personnel, and personal considerations (McMurray, 2010).

The leadership field has faced conflicts over definitional issues and theoretical adequacy.

The general definition of leadership is drawn from charismatic imagery, the measurement of leadership is undertaken with technique designed to study managers or military officers, and the stereotype which often dominates selection of leaders is rather Hollywood-like. Leadership is not unique in its problematic progression to maturity (Coglisera, 2004). 
Leadership is commonly understood as the use of influence to encourage participation in achieving set goals (Yukl, 2006). The leadership process involves the leader's personality and behaviors, the follower's perception of the leader and the context within which the interaction takes place (Antonakis et al., 2004). Central to the concept of leadership is the relationship, that taking place between leaders and followers. Leaders must structure or restructure situations, perceptions and expectations of group members. Hence leadership extends beyond an individual's possession of a certain set of traits or a prescribed set of behaviors exercised in response to a defined situation. Leadership is a relational process between leader and followers, and is molded by the context (McCallum, 2009). Moreover, studies still primarily concentrate on top-level leadership of entire organizations. A major move forward however is that new leadership research moves the emphasis to leadership of organizations rather than leadership in organizations (Hunt, 1999).

This approach is supported by the latest research of Alban-Metcalfe and Alimo-Metcalfe (2007, p. 116) who claim that leadership is a relational process that needs to go beyond the "outdated notions of 'heroic' models of leadership that encourage adulation of a few gifted individuals at the top of organizations". Styles of leadership consistent with this theory include transformational, transactional, charismatic, visionary or inspirational leadership (Hunt, 1999). They emphasis the leader's role in the organizational culture (Bryman et al., 1996) thereby emphasizing the importance of context-specific studies on leadership.

Understanding the differences between transactional and transformational leadership is vital because of the implication that a leader can be both transactional and transformational (Bryman, 1996). Burns (1978) developed the initial concepts of transactional and transformational leadership. He defined transformational leadership as the process of pursuing collective goals through the mutual tapping of leaders' and followers' motive bases towards the achievement of the intended change. In comparison, transactional leadership is a process of exchanging one thing for another among leaders and followers.

Similarly, Bass (1990) defined transformational leadership as superior leadership performance that occurs when leaders broaden and elevate the interests of their employees, and inspire followers to look beyond their own self-interest for the good of the group. On the other hand, transactional leaders help followers identify what must be done to accomplish desired goals. Transactional leadership involves daily exchanges between a leader and subordinates, and is necessary for achieving routine performance that is agreed on between leaders and subordinates. Transactional leadership is built on reciprocity - the idea that the relationships between leaders and their followers develop from the exchange of some reward such as performance ratings, pay, recognition, and praise. It involves leaders clarifying goals and objectives, and communicating to organize tasks and activities with the co-operation of their employees to ensure that wider organizational goals are met (McCallum, 2009). Such a relationship depends on hierarchy and the ability to work through this mode of exchange. It requires leadership skills such as the ability to obtain results; to control through structures and processes; to solve problems; to plan and organize; and to work within the structures and boundaries of the organization (McMurray, 2010).

Transformational leadership, on the other hand, is concerned with engaging the hearts and minds of others. It works to help all parties achieve greater motivation, satisfaction and a greater sense of achievement. It requires trust, concern and facilitation rather than direct 
control. The skills required are concerned with establishing a long-term vision, empowering people to control them, coaching, and developing others and challenging the culture to change. In transformational leadership, the power of the leader comes from creating understanding and trust. In contrast, in transactional leadership, power is based much more on the notion of hierarchy and position (McMurray, 2010).

Transformational leadership studies have seen the onset of new research and theory anchored in neo-charismatic approaches thereby providing a paradigm shift revitalizing the field (Lowe and Gardner, 2001). Modern leadership research emphasises team structures, participative management, and increasing individual empowerment, with leadership now being distributed among members of the organization. Yukl (2006) suggests "an alternative perspective would be to describe leadership as a shared process of enhancing the collective and individual capacity of people to accomplish their work roles effectively". This definition essentially sees leadership as facilitating others' performance, and relates well to the view that leadership is found throughout all levels of an organization, not just among senior executives.

For leadership to be effective, Chemers (2002) suggests that leaders must focus on their credibility and legitimacy with followers, the development of a relationship via identification of followers' needs and motivations, and deploying resources as to draw the best out of followers in order to meet established goals. This means leaders must embrace change, motivating and inspiring followers to move in a desired direction (McCallum, 2009).

Leadership effectiveness can also be driven by relationships beyond one's immediate subordinates. We follow the lead of Balkundi and Kilduff (2006) who understand leadership as "social capital that collects around certain individuals". Furthermore, leadership is based "on the acuity of their social perceptions and the structure of their social ties" (Balkundi and Kilduff, 2006). This highlights to the importance of relationships both within and among organizations. An effective leader understands social network relationships among organization members and also between members and others beyond the organization boundaries, and is able to leverage individuals' personal networks for the benefit of the organization (Balkundi and Kilduff, 2006). Leaders of projects, especially those involving information systems, need to be able build trust in order to make use of the social capital that is critical for success of such projects (Tansley and Newell, 2007). Responsible leaders also think beyond projects, and beyond their immediate organizations, considering how to build relationships and ties that create stakeholder social capital.

In sum, leadership involves the ability to build and maintain relationships, cope with change, motivate and inspire others and deploy resources (McCallum, 2009).

\subsection{Employee engagement}

Employee engagement has become a widely used and popular term (Robinson et al., 2004). However, most of what has been written about employee engagement can be found in practitioner journals where it has its basis in practice rather than theory and empirical research. As noted by Robinson et al. (2004), there has been surprisingly little academic and empirical research on a topic that has become so popular. As a result, employee engagement has the appearance of being some what faddish or what some might call, "old wine in a new bottle." To make matters worse, employee engagement has been defined in many different ways and the definitions and measures often sound like other better known and established constructs like 
organizational commitment and organizational citizenship behavior (Robinson et al., 2004).Most often it has been defined as emotional and intellectual commitment to the organization or the amount of discretionary effort exhibited by employees in their jobs (Saks, 2006).

In fact, although there is some broad agreement about the type of factors included in "employee engagement", there is a lack of clarity about its definition and measurement.

Kahn (1990) was the first researcher to posit that engagement means the psychological presence of an employee when executing his organizational task. Kahn tried to discover the psychological circumstances essential to justify moment of individual engagements and individual disengagements amid employees in diverse conditions at work. He applied the observation techniques and interviews to accomplish a qualitative research of individual engagements and disengagement at work of 16 counselors of a summer camp and 16 employees of an architectural firm. He established that individuals portray upon themselves to a changeable extent at the same time as executing job roles with the obligation of presence; cognitively, emotionally and physically in different tasks they carry out; noting that the employees could decide to retreat or disengage from their job roles and organizational tasks. This position laid a conceptual foundation for Gallup Organization.

Therefore, it may not be wrong to say that the term employee engagement as it is presently used is a construct coined by the Gallup Organization (2005), after 25 years of research though engagement was first conceptualized and defined by Kahn as "The "harnessing of organizational members' selves to their work roles; in engagement, people employ and express themselves physically, cognitively and emotionally during role performances" (Kahn, 1990). Harter et al., (2002) further defined employee engagement as "the individual's involvement and satisfaction as well as enthusiasm for work". Robinson et al. $(2004$, p. 9) give a definition of engagement as, "A positive attitude held by the employee towards the organization and its values. An engaged employee is aware of business context, and works with colleagues to improve performance within the job for the benefit of the organization".

Employee engagement is the level of commitment and involvement an employee has towards his or her organization and its values. The construct of employee engagement is relatively new for HRM and appeared in the literature for nearly two decades (Robinson et al., 2004). Saks (2006) noted that engagement is most closely associated with the existing construct of job involvement and flow.

International Survey Research (2003) described employee engagement as the practice by which a firm enhances the commitment and contribution of its human resources to achieve greater business outcomes. The International Survey Research resolved that employee engagement is a mixture of an employee's cognitive, behavioral and affective dedication to his or her organization (Saks, 2006).

Engagement has to do with how individuals employ themselves in the performance of their job. Furthermore, engagement involves the active use of emotions and behaviors in addition to cognitions. Ivan et al. (2010) also suggest that "engagement may be thought of as an antecedent to job involvement in that individuals who experience deep engagement in their roles should come to identify with their jobs" (Ivan et al., 2010). In general, the items in most engagement surveys focus on the aspects of engagement that are most obviously related to "positive" employee behavior, and cover established psychological concepts, such as 
organizational citizenship and organizational commitment and attachment (Ivan et al., 2010). For example, the Utrecht Work Engagement Survey (Schaufeli et al., 2006) concentrates on three factors: vigor, dedication and absorption. They are defined in the following:

\subsubsection{Vigor}

Vigor is characterized as high levels of energy and mental resilience while working, the willingness to invest effort in one's work and persistence even in the face of difficulties (Schaufeli, et al., 2006).Taipale et al. (2011), mentioned vigor refers to energetic working; being ambitions enough to work hard, even in difficult situations. So in workplace vigor demonstrated a willing to contribute energy into a task, an ability to avoid fatigue and demonstrating persistence in completing a task (Weidert, 2011).

\subsubsection{Dedication}

Dedication refers to being strongly involved in one's work (Schaufeli et al., 2006). It is linked to the experience of meaningful work and dedication in work signals that an individual's pride in his work, finding its content inspiring (Taipale et al. 2011). Based on dedication a person experiences a sense of significance, enthusiasm, inspiration, pride, and challenge by completing his task (Cole et al., 2011).

\subsubsection{Absorption}

Absorption is characterized by being fully concentrated and happily engrossed in one's work, whereby time passes quickly and one has difficulties with detaching oneself from work (Schaufeli, et al., 2006). In other words it refers to personal immersion in work, from which one gets pleasure. It also indicates that a person is concentrated on his work and finds it rewarding (Maslach et al., 2001).

The Gallup Workplace Audit focuses on factors such as clarity - knowing what's expected and control (input and opportunity). By and large practitioners and researchers views of engagement embody the three core concepts of Attachment, Commitment and Organisational Citizenship. These concepts reflect a focus on the aspects of engagement that are likely to be most directly involved in driving positive employee behaviour (Ivan et al., 2010).

Rothbard (2001, p. 656) also defines engagement as psychological presence but goes further to state that it involves two critical components: attention and absorption. Attention refers to "cognitive availability and the amount of time one spends thinking about a role" while absorption "means being engrossed in a role and refers to the intensity of one's focus on a role."

Findings of many research works agree that employee engagement could be a strong factor for organizational performance and success, as it seems to have a significant potential to affect employee retention, their loyalty and productivity, and also with some link to customer satisfaction, organizational reputation and the overall stakeholder value. Employee engagement is a broad construct that touches nearly all branches of human resource management facets known hitherto. If every component of human resource were not well addressed with proper approach, employees would fail to fully engage themselves in their job roles thereby leading to mismanagement (Markos and Sridevi, 2010). Employee engagement is crucial for any organization. Engaged employees contribute to the foundation line of any business and their engagement is echoed in their services to clients and customers. By so doing, engaged employees are helping to generate more patronage and customers loyalty. A highly engaged customer buys more products and services, refers more potential customers to that 
same company, stays longer and gives more feedback, which in turn, gives organization a huge profitability (Ologbo, 2012).

In summary, although the definition and meaning of engagement in the practitioner literature often overlaps with other constructs, in the academic literature it has been defined as a distinct and unique construct that consists of cognitive, emotional, and behavioral components that are associated with individual role performance. Furthermore, engagement is distinguishable from several related constructs, most notably organizational commitment, organizational citizenship behavior, and job involvement (Ivan et al., 2010).

\subsection{Knowledge transfer}

Knowledge is quickly becoming the prime source of wealth in the world, not only for corporations and individuals but also - and perhaps even more so - for nations and societies. As individuals, organizations and multinational corporations struggle to compete in the global economy, they need more than sound technology; they also must have the support of integrated national and societal structures to help them manage their constant demand for new knowledge. Such knowledge-intensive assets include value-creating networks, communities of practice, advisory committees, educational and teaching resources, and research and R\&D capacities. Integrated framework of knowledge assets vastly differ from the infrastructure of traditional agricultural and industrial societies, which relied heavily on tangible assets such as land, labor and machines (Parent et al., 2007).

The emergence of knowledge management discipline has coincided with the development of the global knowledge based economy in which emphasis has been shifted from traditional factors of production, namely capital, land and labor, to knowledge. Parallel to this, Drucker (1992) suggests the classical factors are becoming secondary to knowledge as the primary resource for the economy. Several researchers argue the effective management of knowledge is becoming a critical ingredient for organisations seeking to ensure sustainable strategic competitive advantages. Davenport and Bibby (1999), for example, point out that in the knowledge-based economy competitiveness is increasingly based upon access to knowledge in the form of skills and capabilities. Knowledge transfer seems to be one of the main themes of knowledge management which involves the use and creation of value from organisational knowledge. Against this backdrop, successful accomplishment of knowledge transfer within an organization or between organisations has a great role to play (Jasimuddin, 2008).

It is well known, however, that knowledge is generally difficult to transfer. Many researchers have focused on the importance of knowledge transfer to an organization's competitive advantage (Cavusgil et al., 2003).

Other researchers provide numerous examples of organizations that have significantly improved their performance by instituting knowledge transfer programs. Hoopes and Postrel (1999) take a different tack by demonstrating instances when the lack of information sharing by employees has increased production costs significantly. Blumentritt and Johnston (1999, p. 287) suggest, on a more macro level, that: "the ability to identify, locate and deliver information and knowledge to a point of valuable application is transforming existing industries, and facilitating the emergence of entirely new industries".

But the task of transferring knowledge successfully is far from straightforward. O'Dell and Grayson (1999) report on research suggesting that the transfer of "best practices" between 
two divisions of the same organization takes, on average, 27 months to complete. Both Argote (1999) and Szulanski (1996) determined that the effectiveness of knowledge transfer initiatives varies significantly among organizations, and Argote et al. (2000) note that knowledge transfer initiatives often fall far short of delivering on all the sought-after results (Parent et al., 2007). Managing and integrating inter-organizational knowledge transfer on a firm level has advantages compared to managing knowledge transfer projects independently from each other. Knowledge can be transferred at lower costs or higher quality compared to transfer in independent projects. Advantages result from systematically managing knowledge transfer in the relationship to partners across functional or organizational barriers of a center (Hutzschenreuter et al., 2010).

\subsubsection{A brief history of knowledge transfer theory}

Different models or paradigms of organizational knowledge transfer advance various theories as to why it often remains difficult. Early organizational knowledge transfer models viewed knowledge as an object that could be passed on mechanistically from the creator to a translator who would adapt it in order to transmit the information to the user. Within this process, the user was generally viewed as a passive actor or receptacle of knowledge, and the context within which the transfer occurred was typically ignored. These classical models implied a hierarchical top-down relationship between the generator of knowledge who holds the resource (knowledge) and the user (receptacle) who is locked into a dependency stance (Parent et al., 2007).

Numerous authors have criticized this linear model of knowledge transfer for ignoring the reality of both the context in which the new knowledge was generated, and the one within which it will be used. Other models of knowledge transfer and adult learning, such as Bouchard and Gelinas's spiral model; Lewin's (1951) cycle of adult learning; Kolb and Fry's (1975) model of experiential learning; and Honey and Mumford's (1982) typology of learners, all focused on the experiential process of transferring theoretical knowledge to practical knowledge by using knowledge in a real-life setting (Parent et al., 2007).

The latest models to capture the imagination of the research and practice communities are the communities-of-practice model and the knowledge network model. The communities-ofpractice model has been described as "groups of people informally bound together by shared expertise and passion for a joint enterprise" (Wenger and Snyder, 2000, p. 139). Communities of practice cannot be mandated, but they can be encouraged, supported and promoted. They are generally motivated by people realizing that they could benefit by sharing knowledge, insights and experiences with others with similar goals; they typically form around best practices or common pursuits. Because communities of practice generally focus on informal, voluntary gatherings of individuals based on shared interests, they are sometimes seen by organizations as "unmanageable" endeavors (Parent et al., 2007). Best-practice and businessopportunity networks, on the other hand, which have more organizational support, are believed to contribute directly to the bottom line. For example, Bu“chel and Raub (2002, p. 587) believe that "the most valuable activities in knowledge management focus on creating knowledge networks that extend beyond the traditional concept of communities of practice. "Business Opportunity" and "Best Practice Transfer" networks have been shown as directly contribute to the creation of value within firms". 
Most of the attention on knowledge transfer has focused on it as a process. The authors' experience in a broad variety of organizational settings, ranging from highly creative research organizations to more practical manufacturing settings, supports Szulanski's view of the importance of context. However, in addition to context, the authors' current research also indicates that knowledge transfer capacity within the entire social system can pose significant challenges to effective knowledge transfer (Parent et al., 2007).

\subsubsection{The dynamic knowledge transfer capacity model}

The Dyna mic Knowledge Transfer Capacity (DKNOWLEDGE TRANSFERC) model advances a new systemic and generic framework to identify the components required for social systems to generate, disseminate and use new knowledge to meet their needs. By applying a holistic, systems-thinking focus to knowledge transfer, one can begin to appreciate knowledge transfer as linked to the relationships between and within systems - including their systems of needs, goals and processes. This systemic perspective allows viewing knowledge transfer from both how knowledge gets transferred (the process), and also what capacities the system possesses for knowledge transfer to succeed. As all systems have limits, the model takes into account the boundaries within which knowledge transfer typically occurs (Parent et al., 2007).

In contrast to the more traditional knowledge transfer models that describe knowledge transfer as a process, the DKNOWLEDGE TRANSFERC model focuses on the components a social system must possess for knowledge transfer to occur, or put it, the "assets" the system has to play the game. As illustrated in Figure 1, the model includes two pre-existing conditions (need and prior knowledge) and four capacities. These distinct components are described in more detail in the following pages. Clarifying what new knowledge the system needs, the initial identification of the need also serves to clarify the actors or special interest groups that must be involved in solving the problem, as well as the current state of knowledge, tacit and explicit, possessed by the system (Parent et al., 2007).

Generative capacity refers to the ability to discover or improve knowledge and the processes, technologies, products and services that derive from it. It is based on the system's intellectual and creative capital, which is present among its members, research infrastructure and alliances. Disseminative capacity denotes the ability to contextualize, format, adapt, translate and diffuse knowledge through a social and/or technological network and to build commitment from stakeholders. This ability is generally based on the existence of an articulated social network (social capital including strong and weak ties), brokers, and other intermediaries, including support by a technological and social infrastructure of communications. Absorptive capacity, initially conceptualized by Cohen and Levinthal (1990), is defined here as the ability to recognize the value of new external knowledge, assimilate it and apply it to address relevant issues for a system's stakeholders.

Absorptive capacity is typically found in environments that possess prior related knowledge, a readiness to change, trust between partners, flexible and adaptable work organizations and management support. Finally, adaptive and responsive capacity refers to the ability to continuously learn and renew elements of the knowledge transferring system in use, for constant change and improvement. It is based on prior continuous learning experience, visionary and critical thinking, distributed leadership among stakeholders, multiple feedback loops and monitoring mechanisms. All four of these capacities are necessary to varying degrees 
for a social system (network, organization, society, etc.) to be able to transfer knowledge successfully (Parent et al., 2007).

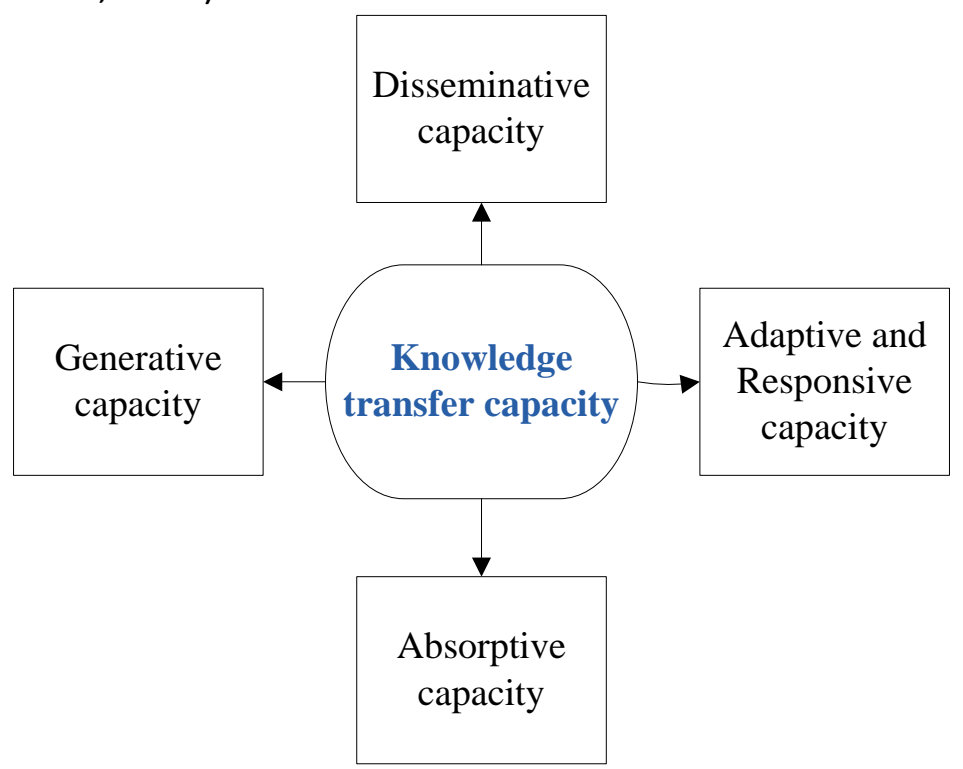

Figure 1 the dynamic knowledge transfer capacity model (Parent et al., 2007)

\section{Development of hypotheses}

The main objective of this study is to investigate the relationship between organizational culture, leadership style, employee engagement and knowledge transfer (as antecedents of knowledge transfer). As a fact we consider these three factors as three wide effective scopes of KNOWLEDGE TRANSFER. At organization level, we consumed organizational culture. At management level, we consumed leadership style and the relationship between leader and members. At individual level, we conducted employee engagement to assess their commitment.

Some previous researchers investigated these relationships in their studies. For example, Wang et al. (2011) found that organizational culture plays a critical role in knowledge creation capability. Moreover, Tseng (2010) indicated that an adhocracy culture enables knowledge conversion and enhances corporate performance more than clan and hierarchy cultures. In the other hand, Singh's (2008) research findings indicate directive as well as supportive styles of leadership to be significantly and negatively associated with the art of knowledge management practices. It also depicts that consulting and delegating styles of leadership are positively and significantly related with managing knowledge in a software organization. Finally, only the delegating mode of leadership behaviors was found to be significant in predicting creation as well as management of knowledge for competitive advantage in software firms in India. The results of Politis's (2001) indicate that the leadership styles that involve human interaction and encourage participative decision-making processes are positively related to the skills and traits that are essential for knowledge management. As Crawford (2005) found Knowledge management behaviors were significantly predicted by transformational leadership. Williams in 2012 argued that the leadership role for learning and knowledge management needs to focus on four main areas - promoting common purpose, developing a collaborative culture, facilitating multi-disciplinary teamwork, and developing learning and knowledge management 
strategies. Moreover, in 2009, Thompson and his colleagues found that Engagement of information is a necessary step before knowledge can be effectively transferred to a receiver. Engagement is defined as an act whereby the receiver of the information actively uses the information by applying it to specific tasks.

Therefore, it was assumed that:

H1. Organizational culture, leadership style and employee engagement are significant antecedents of knowledge transfer in organizations.

H2. Organizational culture is positively related to knowledge transfer in organizations.

H3. Leadership style is positively related to knowledge transfer in organizations.

H4. Employee engagement is positively related to knowledge transfer in organizations.

\section{Method}

\subsection{Research site and participants}

Data were collected with the help of a structured questionnaire personally distributed by the authors to 300 professionals working in over 8 software organizations.

These organizations were situated in the Isfahan city of Iran and each employed more than 50 software professionals. Only those questionnaires that were returned within two weeks of their distribution were considered usable for the study. A total of 268 questionnaires (a response rate of 89.33 percent) were returned within the stipulated time. After deleting the questionnaires that were incomplete, a sample of usable 250 responses, representing a response rate of 83.33 percent, was considered for the final analysis. Of these, 184 were males and 66 were females, over 70 percent were in the range of 20 to 35 years. A young sample is representative of the actual software professional population. Their mean tenure in the organization was 3.5 years. Respondents were asked not to sign or give any form of identification to ensure the anonymity of their responses. Care was taken to include only those respondents who had worked with their supervisor for over six months. This was necessary to make sure that the subordinates were in a position to assess the quality of interaction with their supervisors.

\subsection{Measures}

To assess the hypotheses, we conducted the multi dimensional survey with five parts. In the first part, a series of single-statement items were used to collect information on participants' demographic variables such as age, gender, and tenure. The second part was related to organizational culture. Organizational culture in software companies can be operationalized as three variables: achievement/innovation/competence (AIC), cooperation/supportiveness/ responsiveness (CSR), and emphasis on rewards (ER) (Shim, 2010). Organizational culture is measured using a scale of 32 survey items taken from the workforce retention study that include all items related to AIC, CSR, and ER. Each survey item has a 5 point Likert scale from 1 (strongly disagree) to 5 (strongly agree). In the third part, the quality of exchange between leader and members was assessed using a ten-item quality of interaction scale (Bhal and Ansari, $2000,2009)$. This was a two-dimensional scale, based on the conceptualization by Dienesch and Liden (1986). The respondents were asked to rate the statements on a five-point scale (1=not at all true; 5=very true) as to how true the statements were to their relationship with their immediate supervisor. Sample items include, "How much responsibility does he/she take for 
the jobs that are to be done together by you and him/her?", "How much do you help each other in personal matters?" In the fourth part, we applied UWES. Many researchers constructed the Utrecht Work Engagement Scale (UWES; Schaufeli \& Bakker, 2003) to assess three dimensions of vigor, dedication, and absorption (Cole et al. 2011). The UWES has been used by many studies and has obtained acceptable reliability of scores. The questions of this scale for each dimension assess the engagement of employees by a five-point scale. For measuring the knowledge transfer capacity, in the last part, we applied the dynamic knowledge transfer capacity model by four dimensions of:

- Generative capacity;

- Disseminative capacity;

- Absorptive capacity;

- Responsive capacity (Parent et al., 2007).

We designed 5 survey items for each of these dimensions in order to rate them on five-point scale. Confirmatory factor analysis (CFA) test is used to examine the factor validity of the scales used as indicators of four variables of organizational culture, leadership style, employee engagement and knowledge transfer. The results of the CFA test in this study supported the validity of the measurement model. Cronbach's alpha test is used to determine the internal consistency of items in a survey instrument. It is interpreted as the percent of variance in the observed scale and it would also explain the hypothetical true scale composed of all possible items (Hatcher, 1994). The alpha reliabilities of all variables employed in this study are acceptable.

\section{Results}

The model fit of the research model in this study was tested using AMOS 18.0. Researchers typically employ different indices to determine model fit. Four measures were used to assess the fit of structural models: the goodness of fit index (GFI), the adjusted goodness of fit index (AGFI), comparative fit index (CFI) and root mean square error of approximation (RMSEA).

First a single-factor model (for all the three study variables) was estimated organizational Culture, leadership style, and employee engagement. This model turned out to be a very poor fit to the data (CMIN (x 2/df) =14.82, $p=0.01, \mathrm{GFI}=0.60, \mathrm{AGFI}=0.47, \mathrm{CFI}=0.38, \mathrm{RMSEA}=0.14$ ). Next, the hypothesized (three-factor) model was tested. Given the number of variables, the results of the CFA provided a reasonable model fit $(\mathrm{CMIN}(x 2 / \mathrm{df})=2.19, \mathrm{p}=0.01, \mathrm{GFI}=0.89$, $\mathrm{AGFI}=0.85, \mathrm{CFI}=0: 91, \mathrm{RMSEA}=0.06)$. As can be seen, the hypothesized three-factor model showed much improved $\mathrm{x}^{2}$ and fit statistics, providing support to our three-factor model. All the items were significant predictors of their respective latent variables. Therefore, the hypothesis 1 was accepted. As we assumed in hypothesis 2, there was a significant relationship between organizational culture and knowledge transfer $(\beta=0.818, C . R=6.778, p=0.01)$. The indicators of $(\beta=0.773, C . R=6.105, p=0.01)$ provides support to the third hypothesis which mentioned the significant relationship between leadership style and knowledge transfer. As we predicted, the relationship between employee engagement and knowledge transfer is positive and significant $(\beta=0.706, C . R=5.864, p=0.01)$. 


\section{Discussion}

In this competitive world what seem important are new methods of capturing competitive advantages. Knowledge transfer as one of this vital process can help managers to develop their companies. In previous researches knowledge transfer have been studied as effective variable, but none of them consider three elements of organizational Culture, leadership style, and employee engagement as what can affect on knowledge transfer. As findings indicate, appropriate organizational culture can improve knowledge transfer. The important role of managers in this way is to prepare proper environment for knowledge sharing in organizations. Another important factor is leadership style which can improve transferring knowledge in organizations. The results indicate that not only transformational leadership style, but also the style which is fit with the organizational environment and culture can enhance knowledge transfer. In the other hand, powerful and effective leaders can improve employee engagement and commitment wile this influences on knowledge transfer. Employees who are more engaged in work, are more intensive to share knowledge within their work environment. The results of the present study indicate that all three factors of organizational Culture, leadership style, and employee engagement are strongly related to the knowledge transferring among organizations. These three factors include organizational, managerial and membership aspects.

\section{Implication}

The preset study by focusing on three aspects of culture, leadership and engagement, helps managers to consider wide content of knowledge transfer among their organizations.

Culture aspect of knowledge transfer is out of managers' control while their leadership styles can be contingent with organizations conditions. Managers by paying enough attention to this under control variable can enhance culture in order to improve employee engagement. Previous scholars proved that employee engagement in today's world can be identified as competitive advantage.

\section{Limitation}

In the preset study, all the data were collected through self-reports, which may be limited. However, recent research suggests that self-reported data are not as limited as was previously believed and that people often accurately perceive their social environment. Further, selfreports are also likely to be influenced by social desirability. Although this bias cannot be ruled out, some researchers have shown that social desirability may not be a source of bias in measuring organizational perceptions (Bhal et al., 2009).

\section{References}

- Alban-Metcalfe, J. and Alimo-Metcalfe, B. (2007), "Development of a private sector version of the (engaging) transformational leadership questionnaire", Leadership \& Organization Development Journal, Vol. 28 No. 2, pp. 104-21

- Andrewa, Ologbo; Sofianb, Saudah (2012) Individual Factors and Work Outcomes of Employee Engagement Procedia, Social and Behavioral Sciences, 40, 498 - 508 
- Antonakis, J., Cianciolo, A.T. and Sternberg, R.J. (2004), "Leadership: past, present, and future", in Antonakis, J., Cianciolo, A.J. and Sternberg, R.J. (Eds), The Nature of Leadership, Sage, Thousand Oaks, CA, pp. 1-16.

- Balkundi, P. and Kilduff, M. (2006), "The ties that lead: a social network approach to leadership", Leadership Quarterly, Vol. 17, pp. 419-39.

- Bass, M.B. (1990), "From transformational to transactional leadership: learning to share the vision", Organizational Dynamics, Vol. 18 No. 3, pp. 19-36.

- Bates, S. (2004) Getting engaged: Half of your workforce may be just going through the motions HR Magazine, 49: 44-51.

- Bhal, K.T. and Ansari, M.A. (2000), Managing Dyadic Interactions in Organizational Leadership, Sage, New Delhi.

- Brocke, Jan vom; Sinnl, Theresa (2011) Culture in business process management: a literature review, Business Process Management Journal, Vol. 17 No. 2, pp. 357-377

- Bryman, A., Stephens, M. and Campo, C. (1996), "The importance of context: qualitative research and the study of leadership", Leadership Quarterly, Vol. 7 No. 3, pp. 353-70.

- Bu“chel, B. and Raub, S. (2002), "Building knowledge creating value networks", European Management Journal, Vol. 20 No. 6, pp. 587-96.

- $\quad$ Burns, J.M. (1978), Leadership, Harper and Row, New York, NY.

- Cameron, Kim S., and Ettington, Deborah R. (1988) "The Conceptual Foundations of Organizational Culture" In John C. Smart (ed.), Higher Education: Handbook of Theory and Research, Vol. 4. Norwell, Mass.: Kluwer

- Cameron, Kim S; Quinn, Robert E. (2006) Diagnosing and changing organizational culture: based on the competing values framework, John Wiley \& Sons, Inc, Revised edition

- Cavusgil, S.T., Calantone, R.J. and Zhao, Y. (2003), "Tacit knowledge transfer and firm innovation capability", The Journal of Business and Industrial Marketing, Vol. 18 No. 1, pp. 6-22.

- Chemers, M.M. (2002), "Efficacy and effectiveness: integrating models of leadership and intelligence", in Ott, J.S., Parkes, S.J. and Simpson, R.B. (Eds), Classic Readings in Organizational Behavior, Wadsworth, Belmont, CA, pp. 114-31.

- Coglisera, Claudia; Brigham, Keith H (2004) the intersection of leadership and entrepreneurship: Mutual lessons to be learned, the Leadership Quarterly, 15,771-799

- Cohen, W.M. and Levinthal, D.A. (1990), "Absorptive capacity: a new perspective on learning and innovation", Admi nistrative Science Quarterly, Vol. 35 No. 1, pp. 128-53.

- Cole, M. S; Walter, F; Bedeian, A. G \& O’Boyle, E. H.(2011). “Job burnout and employee engagement: A meta-analytic examination of construct proliferation" Journal of management, Vol. 2, No. 1, pp. 834-848

- Cooke, R. A., \& Szumal, J. L. (2000) Using the Organizational Culture Inventory to understand the operating cultures of organizations. In N. M. Ashkanasy, C. P. M. Wilderom, \& M. F. Peterson (Eds.), Handbook of organizational culture and climate (pp. 147-162). Thousand Oaks, CA: Sage Publications.

- Crawford C.B. (2005) Effects of transformational leadership and organizational position on knowledge management, Journal of Knowledge Management Volume: 9 Issue: 6 
- Davenport, S. and Bibby, D. (1999), "Rethinking a national innovation system: the small country as SME", Technology Analysis and Strategic Management, Vol. 11 No. 3, pp. 431-62.

- Deal, T. E., \& Kennedy, A. A. (1982) Corporate cultures: The rites and rituals of corporate life. Reading, MA: Addison-Wesley.

- Dienesch, R.D. and Liden, R.C. (1986), "Leader-member exchange model of leadership: a critique and further development", Academy of Management Review, Vol. 11, pp. 61834.

- Drucker, P.F. (1992), "The new society of organisations", Harvard Business Review, Vol. 95 No. 5, pp. 95-105.

- Gallup Organization, (2005) Employee Engagement: The Engagement side of the Human sigma Equation. Retrieved from www.gallup.com, On 13th August 2012

- Glisson, C. (2007). Assessing and changing organizational culture and climate for effective services. Research on Social Work Practice, 17(6), 736-747

- Glisson, Charles; Dukes, Denzel; Green, Philip (2006) The effects of the ARC organizational intervention on caseworker turnover, climate, and culture in children's service systems; Child Abuse \& Neglect, 30, 855-880

- Harter, J.K., F.L. Schmidt and T.L. Hayes, (2002) Business-unit-level relationship between employee satisfaction, employee engagement and business outcomes: A meta-analysis. J. Applied Psychol., 87: 268-279.

- Hatcher, L. (1994) A step-by-step approach to using the SAS system for factor analysis and structural equation modeling. Cary, NC: SAS Institute Inc.

- Hooper, N (2006) Companies where people want to work, Weekend Australian Financial Rev., 17-19

- Hoopes, D.G. and Postrel, S. (1999), "Shared knowledge, 'glitches', and product development performance”, Strategic Management Journal, Vol. 20 No. 9, pp. 837-65.

- Hunt, J. G., \& Dodge, G. E. (2000). Leadership deja vu all over again. The Leadership Quarterly, 11(4), 435-458.

- Hunt, J.G. (1999), “Transformational/charismatic leadership's transformation of the field: an historical essay", Leadership Quarterly, Vol. 10, pp. 129-44.

- Hutzschenreuter, Thomas; Horstkotte, Julian (2010) Knowledge transfer to partners: a firm level Perspective, journal of knowledge management, VOL. 14, NO. 3, pp. 428-448

- International Survey Research (2003) Engaged Employee Drives the Bottom Line. Research Summary, Chicago, Illinois, 10-35.

- Jasimuddin, Sajjad M (2008) A holistic view of knowledge management Strategy, journal of knowledge management, VOL 12, NO 2, pp. 57-66

- Kahn, W.A., (1990) Psychological conditions of personal engagement and disengagement at work. Academy Manage. J., 33: 692-724.

- Kanika T. Bhal, Namrata Gulati, Mahfooz A. Ansari, (2009),"Leader-member exchange and subordinate outcomes: test of a mediation model", Leadership \& Organization Development Journal, Vol. 30 Iss: 2 pp. 106 - 125

- Kroeber, A.L. and Kluckhohn, C. (1952), Culture: A Critical Review of Concepts and Definitions, Peaboy Museum, Cambridge, MA. 
- Lowe, B.K. and Gardner, L.W. (2001), "Ten years of the Leadership Quarterly: contributions and challenges for the future", Leadership Quarterly, Vol. 11 No. 4, pp. 459-514.

- Markos, S. and M.S. Sridevi, (2010) Employee engagement: The key to improving performance. Int. J. Bus. Manage., 5: 89-95.

- Maslach, C; Schaufelli, W. B \& Leiter, M. P.(2001) "Job burnout", Annual Review of Psychology, Vol. 52, No. 1, pp. 397- 422

- McCallumShelly, O'Connell David, (2009),"Social capital and leadership development: Building stronger leadership through enhanced relational skills", Leadership \& Organization Development Journal, Vol. 30 Issue: 2, pp. 152 - 166

- McMurray A.J., Pirola-Merlo A., Sarros J.C., Islam M.M., (2010),"Leadership, climate, psychological capital, commitment, and wellbeing in a non-profit organization", Leadership \& Organization Development Journal, Vol. 31 Iss: 5 pp. 436 - 457

- Ouchi, W. G. (1981). Theory Z: How American business can meet the Japanese challenge. Reading, MA: Addison-Wesley

- Parent, Robert, Roy, Mario; St-Jacques, Denis A systems-based dynamic knowledge transfer capacity model, journal of knowledge management, VOL. 11, NO. 6 2007, pp. 81-93

- Politis John D. (2001) the relationship of various leadership styles to knowledge management, Leadership \& Organization Development Journal, Volume: 22 Issue: 8

- Robertson Ivan T., Cooper Cary L., (2010),"Full engagement: the integration of employee engagement and psychological well-being", Leadership \& Organization Development Journal, Vol. 31 Iss: 4, pp. 324 - 336

- Robinson, D., Perryman, S. and Hayday, S. (2004), The Drivers of Employee Engagement, Institute for Employment Studies, Brighton.

- Rothbard, N.P. (2001), "Enriching or depleting? The dynamics of engagement in work and family roles", Administrative Science Quarterly, Vol. 46, pp. 655-84.

- Saks Alan M., (2006),"Antecedents and consequences of employee engagement", Journal of Managerial Psychology, Vol. 21 Issue: 7, pp. 600 - 619

- Schaufeli, W. B \& Bakker, A. B.( 2003). "UWES-Utrecht Work Engagement Scale: Test manual" Department of psychology, Utrecht University, Utrecht.

- Schaufeli, W.B., Bakker, A.B. and Salanova, M. (2006), "The measurement of work engagement with a short questionnaire: a cross-national study", Educational and Psychological Measurement, Vol. 66 No. 4, pp. 701-16.

- Schein, E.H. (2004), Organizational Culture and Leadership, Jossey-Bass, San Francisco, CA

- Shim, Miseung (2010) Factors influencing child welfare employee's turnover: Focusing on organizational culture and climate Children and Youth Services Review, 32, 847-856

- Singh Sanjay Kumar (2008) Role of leadership in knowledge management: a study, Journal of Knowledge Management Volume: 12 Issue: 4

- Taipale, S; Selander, K; Anttila, T \& Natti, A (2011) "Work engagement in eight European countries: the role of job demands, autonomy and social support" Journal of Sociology and Social Policy. Vol. 31, No. 7, pp. 486-504. 
- Tansley, C. and Newell, S. (2007), "Project social capital, leadership and trust: a study of human resource information systems development", Journal of Managerial Psychology, Vol. 22, pp. 350-68.

- Thompson Michael P., Jensen Robert J., DeTienne Kristen (2009) Engaging embedded information: Toward a holistic theory of knowledge transfer in organizations, Competitiveness Review: An International Business Journal incorporating Journal of Global Competitiveness Volume: 19 Issue: 4

- Trice, Harrison, and Beyer, Janice (1993)The Cultures of Work Organizations, Upper Saddle River, N.J.: Prentice Hall

- Tseng Shu-Mei (2010) the correlation between organizational culture and knowledge conversion on corporate performance, Journal of Knowledge Management, Volume: 14 Issue: 2

- Verbeke, W., Volgering, M., \& Hessels, M. (1998) Exploring the conceptual expansion within the field of organizational behavior: Organizational climate and organizational culture. Journal of Management Studies, 35(3), 303-329

- Wang Dong, Su Zhongfeng, Yang Dongtao (2011) Organizational culture and knowledge creation capability, Journal of Knowledge Management, Volume: 15, Issue: 3

- Weidert, J.M (2011) "The physiological measurement of employee engagement". In partial fulfillment of the requirements for the Degree of Master of Science Colorado State University Fort Collins, Colorado

- Wenger, E. and Snyder, W. (2000), "Communities of practice: the organizational frontier", Harvard Business Review, pp. 139-45, January/February.

- Williams Paul (2012) The role of leadership in learning and knowledge for integration, Journal of Integrated Care Volume: 20 Issue: 3

- Yukl, G. (2006), Leadership in Organizations, Pearson Education, Upper Saddle River, NJ.

- Zaccaro, S.J. and Klimoski, R.J. (2001) the Nature of Organizational Leadership, JosseyBass, San Francisco, CA 